\title{
WULPUS \\ An Intelligent Problem Solving Environment Delivering Knowledge Based Help and Explanations in Business Management Simulation
}

\author{
Claus Möbus, Olaf Schröder, Heinz-Jürgen Thole ${ }^{1}$ \\ OFFIS Institute, Escherweg 2, D-26121 Oldenburg, Germany \\ E-Mail: \{moebus, schroeder, thole\}@informatik.uni-oldenburg.de
}

\begin{abstract}
Business mangement simulation plays an increasing role in schooling and post-qualification. In complex simulation games the interrelationships between decisions and results are intransparent. This is one reason for inefficient knowledge acquisition. Another reason is the forward chaining architecture of "classical" simulation games.

In this paper we describe a prototype of a business simulation game based on hypotheses testing and goal oriented backward chaining. Its design is based on a theoretical framework, the IPSE approach (Intelligent Problem Solving Environment). In order to offer help on the students' demand, we integrated a hypotheses testing environment, named "simulation in the simulation". The students may state goals and hypotheses about their reachability and about the consistency of decisions with corporate objectives. The system gives feedback and explains the relations in the business marketing simulation by presenting qualitative information, pricedemand curves, and by using an "enterprise landscape" which contains the decision and result variables of the system, their dependencies, and the qualities of their influences.
\end{abstract}

\section{Introduction}

In managerial schooling and post-qualification management, computer based simulations and management business games are used increasingly to meet education requirements. It is hoped that these systems improve the students' abilities of problem solving, business analysis, and teamwork. In order not to diverge from reality too much (Cadotte, 1990; Eser, 1992), in "classical" simulation games there is a high degree of interrelatedness of their components. This may lead to intransparency. Moreover, in the "classical" simulation game approach, the students make decisions and then inspect the resulting consequences. Thus business simulation games are forward chaining. If no explanations are offered that help to comprehend the relationships between decisions and results, the students get into difficulties. Thus the students have to know a lot before playing the game. The situation is further

${ }^{1}$ We thank Klaus Adam and Hagen von Stuckrad for assisting in the implementation. 
complicated e.g. by the performance of the competitors, and by the fact that effects may occur with time delay.

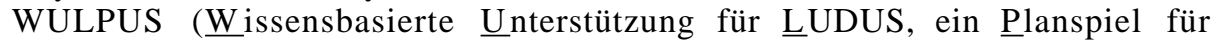

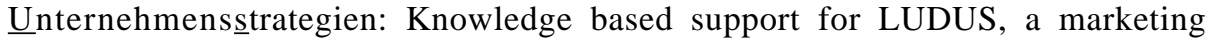
simulation game for business strategies) is an Intelligent Problem Solving Environment (IPSE, Möbus, 1995) designed to make the relationships between the various functional areas of a business enterprise transparent. WULPUS does not require a lot of preknowledge from the student. Rather, the intention is that the student acquires this knowledge while working with WULPUS.

In order to support design decisions for the development of knowledge based help systems, a theoretical framework of problem solving and learning is needed. Our IPSE approach is based on a cognitive science oriented theory of knowledge acquisition, the

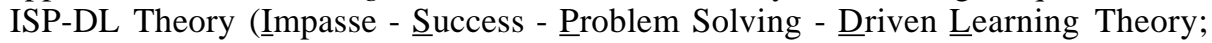
Möbus, Schröder \& Thole, 1994). The theory attempts to integrate impasse-driven learning (Laird, Rosenbloom, \& Newell, 1986; Newell, 1990; van Lehn, 1988; 1991), success driven learning (e. g., Anderson, 1983; 1989), and phases of problem solving (Gollwitzer, 1990; Heckhausen, 1989). According to the theory, the student will look for and appreciate help if he is caught in an impasse. Without an impasse there is no need for help. So WULPUS does not interrupt the student but offers help on request. Furthermore the information should be designed to help the student to overcome the impasse and not to trap into a secondary impasse. Thus the information should refer to his preknowledge as much as possible. One way to realize this principle is to let the student test hypotheses about his solutions, and get help, proposals, and explanations from the IPSE. Therefore in WULPUS the hypotheses testing approach (Möbus, 1995; Möbus, Schröder \& Thole, 1994; Möbus, Thole \& Schröder, 1993) is transferred to the simulation game domain.

A second reason for pursuing the hypotheses testing approach is that stating and testing hypotheses is a key qualification having a beneficial influence on the student's knowledge acquisition process (Shute \& Glaser, 1990).

The domain of WULPUS consists of part of the "classical" business simulation game LUDUS distributed by the German company rado-plan. The main features distinguishing WULPUS from LUDUS and other "classical" business games are:

- Hypotheses testing before the "real simulation step": The hypotheses testing environment allows to state different kind of hypotheses, e.g. the student may state different decision oriented hypotheses one after the other in order to compare their consequences by entering various values for the decision variables. In contrast to LUDUS and other "classical" simulation games, WULPUS supports the decisionmaking by answering the student's question: "What happens if ... ?"

- Forward vs. backward planning: The student may state goal oriented hypotheses by stating his corporate objectives. The system tries to complete each hypothesis about the reachability of the student's goals by computing proposals for decisions consistent with these goals. Furthermore the student may state hypotheses about the consistency of his decisions and the desired results, that is, his corporate objectives, by entering 
both. In contrast to LUDUS, WULPUS supports the decision-making by answering the student's questions: "How is ... reachable?" and "Is ... reachable if ... ?"

- Proposing corrections of inconsistent decisions and corporate objectives. WULPUS gives feedback about the achievability of the student's goals. Furthermore the system offers correction proposals for the decisions if goals cannot be reached.

- Explanation component: WULPUS provides knowledge based explanations by answering the student's questions:

- How did the results occur given my decisions?

-Why are the decision proposals suitable to achieve my goals?

- Why are some goals not reachable?

The remainder of this paper is organized as follows: The next section gives an overview of WULPUS. In the third section, the hypotheses testing facilities of WULPUS are described in some detail. The paper ends with some conlusions.

\section{Description of WULPUS}

The knowledge based business management simulation game WULPUS has been developed to demonstrate an approach to make the interrelations of a complex simulation game transparent. We wanted WULPUS to offer multiple support for the student's decision-making. Therefore the concept of a "simulation in the simulation" has been developed and realized. Before the next "real simulation step" is performed the student has the opportunity to test alternatives. The student may reverse his former decisions and objectives. After restoring the simulation and entering new values the student may start the WULPUS computation again. So the student is able to compare the relationships between the different values of decisions and corporate objectives. To recognize effects with time delay the student may carry out several trial simulation steps one after the other, focusing on the development of the variables he is interested in, e.g. his sales opportunities.

In order to simulate a realistic market, it is necessary that the student be able to vary the competitive companies' goals and decisions as well. Therefore, while using the "simulation in the simulation" for decision-making, the student may enter assumptions about the performance of his competitors.

Furthermore WULPUS supports the knowledge acquisition of the students by offering explanations. Since WULPUS contains an integrated expert knowledge base it is able to explain the interrelationships between the variables of the business management simulation. In addition, if the corparate objectives are not reachable, the student may invoke the explanation component of WULPUS. The explanations are taylored in steps which are presented to the student one by one on demand. The feedback steps are: Firstly the answer (yes / no), secondly a qualitative description of the dependencies, and thirdly quantitative information, e.g. price-demand curves. Thus in WULPUS essential knowledge like price-demand curves is not a prerequisite. Rather, this knowledge is offered by WULPUS on demand in impasse situations.

There is some evidence that novices get into difficulties while learning business management from complex simulation games. Novices have serious problems in 
decision-making. They are not able to explain the consequences of their decisions to themselves without further help owing to the lack of preknowledge. On the other hand they have clear-cut ideas concerning their corporate objectives. This is the reason for the opportunity to work in a goal oriented manner with WULPUS. During the decision-making in the "simulation in the simulation" the student may enter his goals without specifying the decision variables. Now the system computes the values for the unspecified decision variables in backward direction such that the desired results are reachable. So the conventional roles of the dependent and independent variables of a "classical" business management simulation have been exchanged.

Figure 1 shows the flow of working with WULPUS. According to our theoretical position, the task "accomplishing a simulation step in a business management game" may consist of four phases: Deliberating, planning, executing and evaluating (Heckhausen, 1989; Gollwitzer, 1990). In conventional simulation games just the executing phase is supported: Carrying out the "real simulation step": Entering the decisions and retrieving the results (part between the two broken lines of Figure 1). WULPUS also supports the planning and evaluating processes by offering hypotheses testing and explanations. Control is left to the student. Hypotheses testing and demanding explanations are invoked by the student, that is if the student appreciates them and finds them helpful (rounded boxes).

The student may play up to four hypotheses testing simulation steps to recognize time delayed effects of the mix of marketing tools on the sales opportunities (backward pointing arrow on the upper right of Figure 1). He may save each hypothesis in order to compare its results with future hypotheses (backward pointing arrow on the upper left). He may also ask for explanations for any tested hypotheses. After finishing the decision-making concerning the mix of marketing tools the student has to accomplish his internal company policy. The budgeting is constrained by the data attained in the market situation, e.g. the values for sales opportunities, and prices. WULPUS offers explanations to support the student's analysis of the results. For the purpose of comparison of alternatives each step of hypotheses testing for internal planning may be repeated with new values too (backward pointing arrow on the left of the middle part of Figure 1). Furthermore the student may reiterate the hypotheses testing about competition in the market situation, e.g. if it becomes obvious that the values for the sales opportunies and the mix of marketing tools are not suitable for a promising internal budgeting. After finishing the complete decisionmaking process, the real simulation step takes place: Entering decisions and retrieving the results. The student may ask for help by demanding explanations for the unexpected results.

\section{Hypotheses Testing in WULPUS}

Hypotheses testing within a business simulation will be demonstrated by a sample run with WULPUS. Imagine a student's problem is the decision-making for the next "real simulation step". He may make use of the "simulation in the simulation" by stating hypotheses in order to find out whether his corporate objectives are achievable.

\subsection{Hypotheses Testing in the Market Situation}


Figure 2 shows the hypotheses testing environment for the market situation. First the student has to select a product and a market (at the top). WULPUS offers several opportunities to state hypotheses. The student can state the following decisions and goals concerning his own business enterprise (left half from top to bottom):

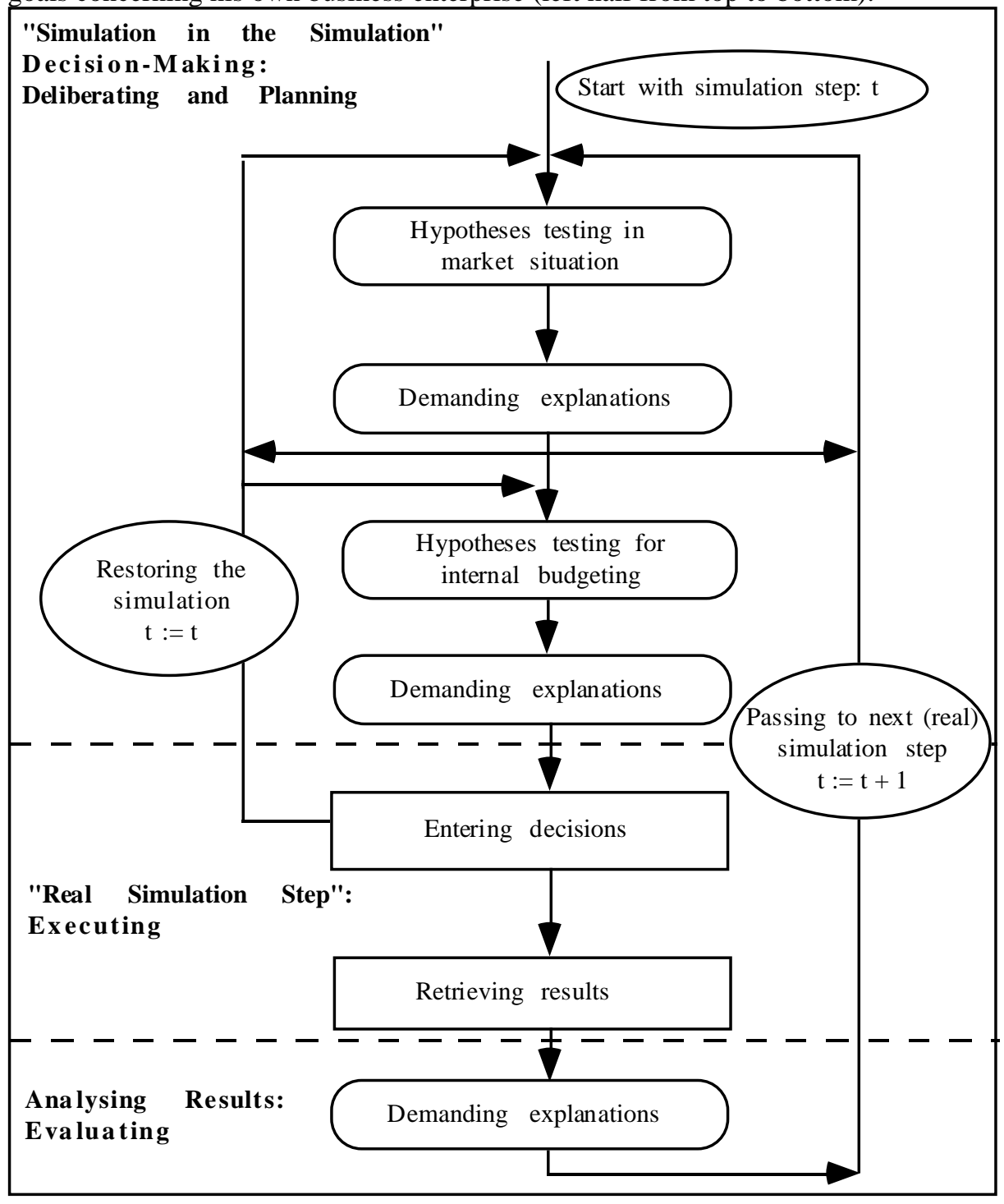

Fig. 1. Overview of WULPUS

The enterprise

- does not change the former (given) decisions for the mix of marketing tools

- decides to use new values for price, advertising, distribution, and research

- pursues the strategy of holding, raising, or decreasing sales opportunities

- sets a value as a goal for the sales opportunities 
The assumptions about the performance of the competitor have to be one of the following (right half from top to bottom of Figure 2): The competitor:

- does not change his former marketing decisions

- decides to use new values for price, advertising, distribution, and research

- pursues an equivalent or a contrary strategy for the sales opportunities

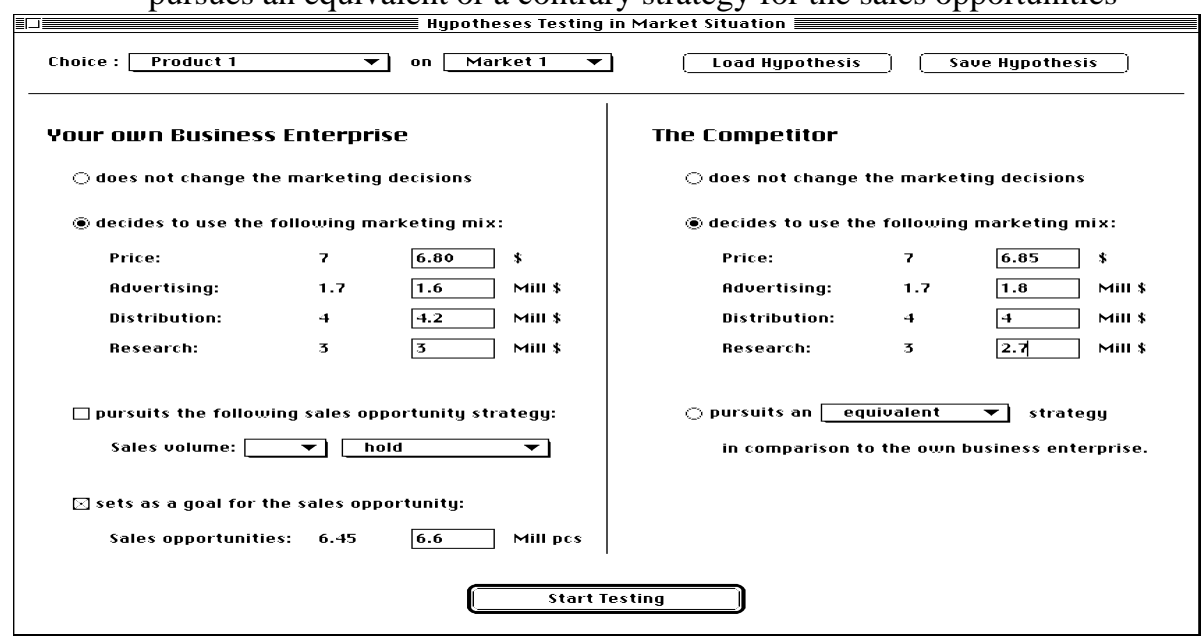

Fig. 2. Consistency hypothesis in the market situation

In the situation depicted in Figure 2, the student may state a consistency hypothesis for product 1 on market 1 . He has entered the goal for his sales opportunities (6.6 million pieces) and a complete set of values for the decision variables "price" $=6.80$ dollars, "advertising" = 1.6 million dollars, "distribution" $=4.2$ million dollars, and "research" = 3 million dollars. The values of the last period are also shown: "price" = 7.00 dollars, and so on. Furthermore in this example the learner makes assumptions about the marketing decisions of his competitor. WULPUS analyzes the hypothesis and then gives feedback on the first level: In this case, the value reached falls below the goal set for the sales opportunities. On the second level of feedback WULPUS provides qualitative proposals about how to change the decision variables in order to reach the goal, e.g. to decrease the price or to decrease advertising. The student may test several consistency hypotheses, but this may be a tedious trial and error process.

Therefore the student may state a goal oriented hypothesis by leaving at least one decision variable unspecified. WULPUS computes the missing value(s) to reach the objective for the sales opportunity. Figure 3 shows the student's hypothesis. The price is left unspecified. WULPUS succeeds in computing a price to reach the goal.

On the third level of feedback, the price-demand curve is presented (Figure 4). Looking at the curve the student sees that a considerably higher price can be achieved by a small reduction in the sales opportunities. So he may decide to test another goal oriented hypothesis. He changes neither the values for advertising, distribution, and research, nor his assumptions about his competitor. But he sets a new, slightly lower goal for sales opportunities: 6.35 million pieces. Now even a price of $\$ 7.50$ is possible. Hypotheses testing can be performed for each product on each market. 


\subsection{Hypotheses Testing for Internal Budgeting}

When the student is satisfied with his marketing decisions, he may start with the internal budgeting. Planning internal budgeting is constrained by the results obtained for the market situation. For internal budgeting, there are the following decision areas besides marketing: personnel policy, production / stocks of goods, machinery, and finances. Furthermore, there are two reports: sales statistics, and profit and loss account. A student may but need not deal with all variables of the decision areas. As an example we will show the finances dialog (Figure 5). The only decision variable is the value for the line of credit. In our example the student does not decide on this but states \$290 million as the goal for the "sum of paying out". Now he invokes the hypothesis test. This means that the student states the hypothesis that his marketing decisions can be made without exceeding 290 million dollars for "sum of paying out". As Figure 6 shows, the values left unspecified in figure 5 have been computed by the system. Values consistent with the hypothesis are marked with a friendly smiley button. WULPUS has marked the value for the "sum of paying out" with a sad button. This indicates an inconsistency discovered: This "sum of paying out"-goal is not reachable, given the decisions made. In order to ask for a correction proposal and explanations the student clicks on the sad button. The correct value displayed by WULPUS is \$ 296.261 million.

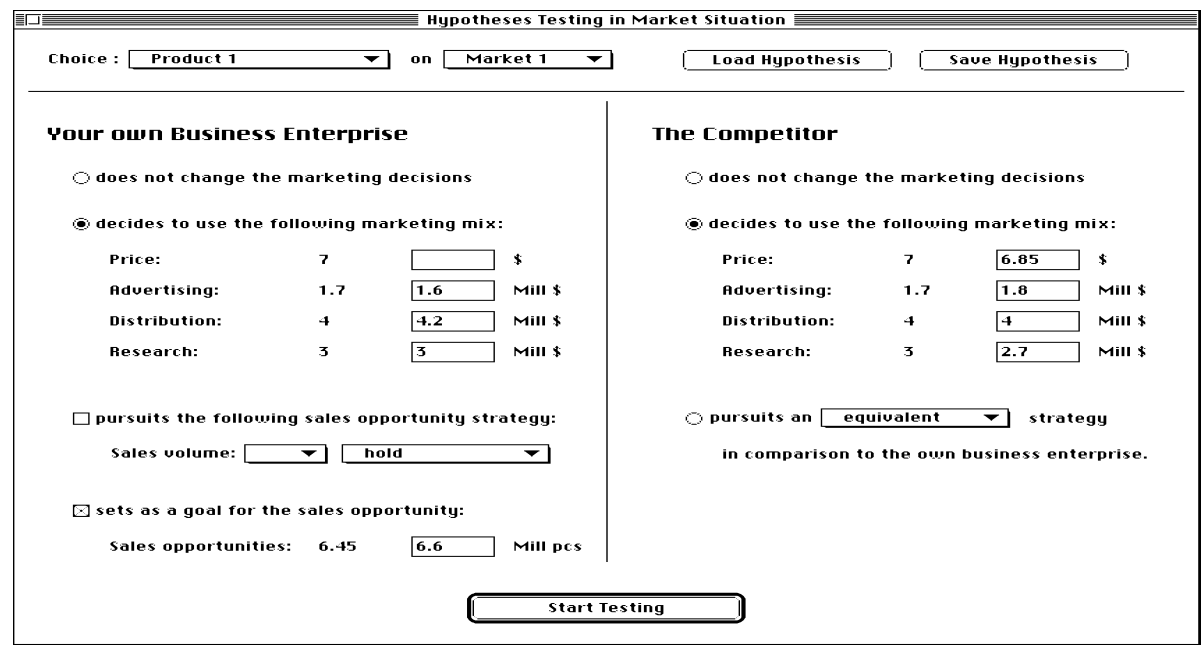

Fig. 3. Goal oriented hypothesis in the market situation

On further request the student may retrieve an overview of the influences on the "sum of paying out". WULPUS opens a landscape of the business enterprise (Figure 7). First the landscape contains only the variable "sum of paying out" and its direct causes (bold ellipses). On demand the landscape is spreading out step by step. The direction of each influence is represented by an arrow. Its quality is symbolized by the sign (+ / -). For example: When the "investments" increase, then the "sum of paying out" will increase too. The student may "walk" through the WULPUS landscape to discover the dependencies between the variables. Reasons for the higher "sum of 
paying out" may be located in the nodes "paying out without respite" and "investments" because these can be contolled by internal budgeting. The student may explore these possibilities, getting hints for the reasons for his undesirably high sum.

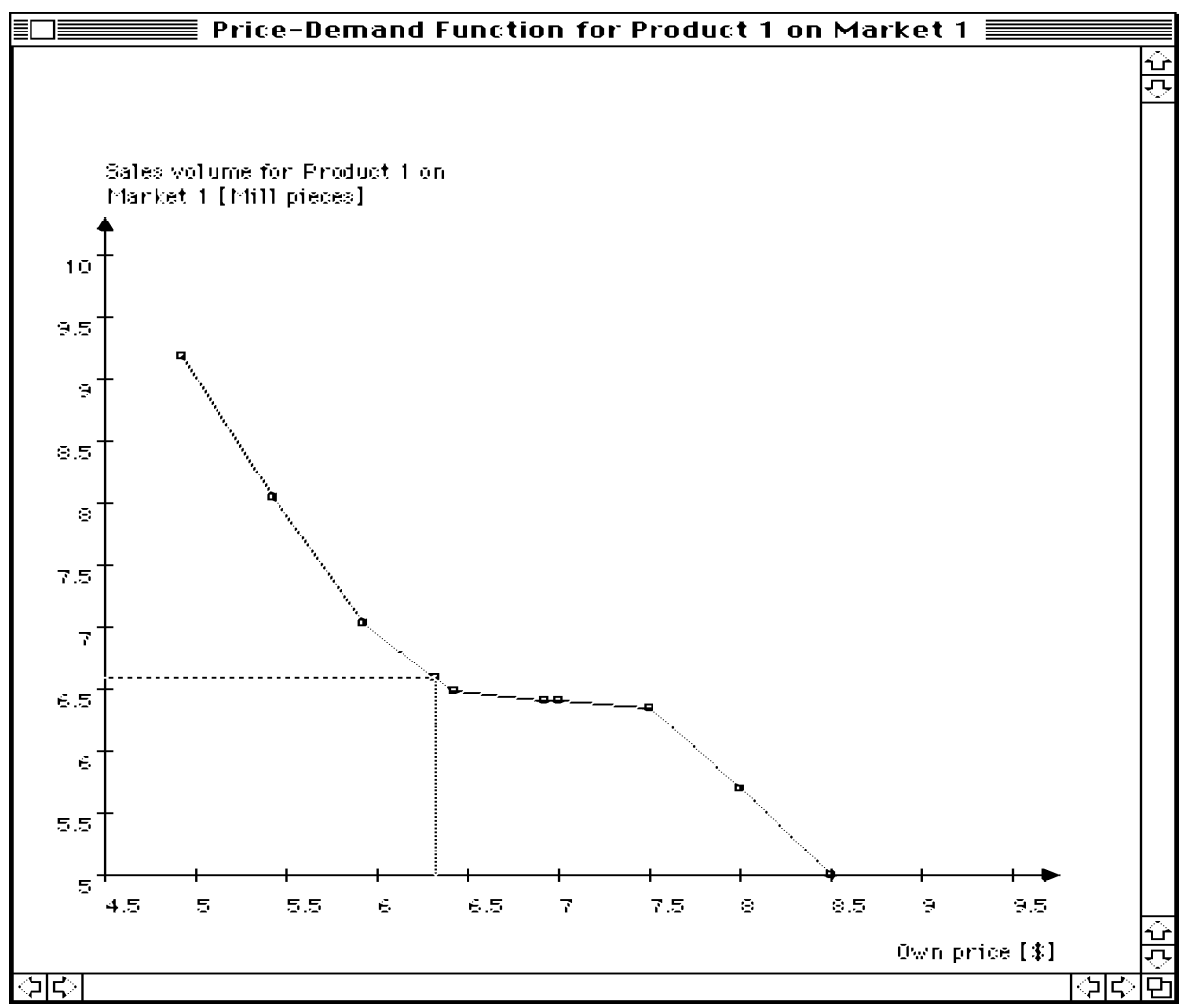

Fig. 4. The price-demand curve corresponding to the goal-oriented hypothesis of Fig. 3 


\begin{tabular}{|c|c|c|c|}
\hline \multicolumn{4}{|c|}{ Finances } \\
\hline Statements of financial positions & old values & Diff. in $\%$ & New val \\
\hline Sales revenues & 228.55 & & \\
\hline Short term credit & 82.7797 & & \\
\hline Line ar credir & 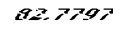 & & \\
\hline Ouerdraft facility & o & & \\
\hline other inpayment & o & & \\
\hline$\Sigma$ Inpayment & 311.329 & & \\
\hline Paying out without respite & 206.524 & & \\
\hline Investments & o & & \\
\hline Redemption for short term credit & 97.2156 & -14.849303 & 82.7797 \\
\hline Redemption for ouerdraft facility & o & o & $\mathbf{0}$ \\
\hline Interest and related expenses & 3.40254 & & \\
\hline $\operatorname{Tax}$ & 4.18731 & & \\
\hline$\Sigma$ Paying out & 311.329 & & 290 \\
\hline Balance & o & & \\
\hline & & All value & n Mill *. \\
\hline & & & $\mathbf{O K}$ \\
\hline
\end{tabular}

Fig. 5. Hypothesis for internal budgeting

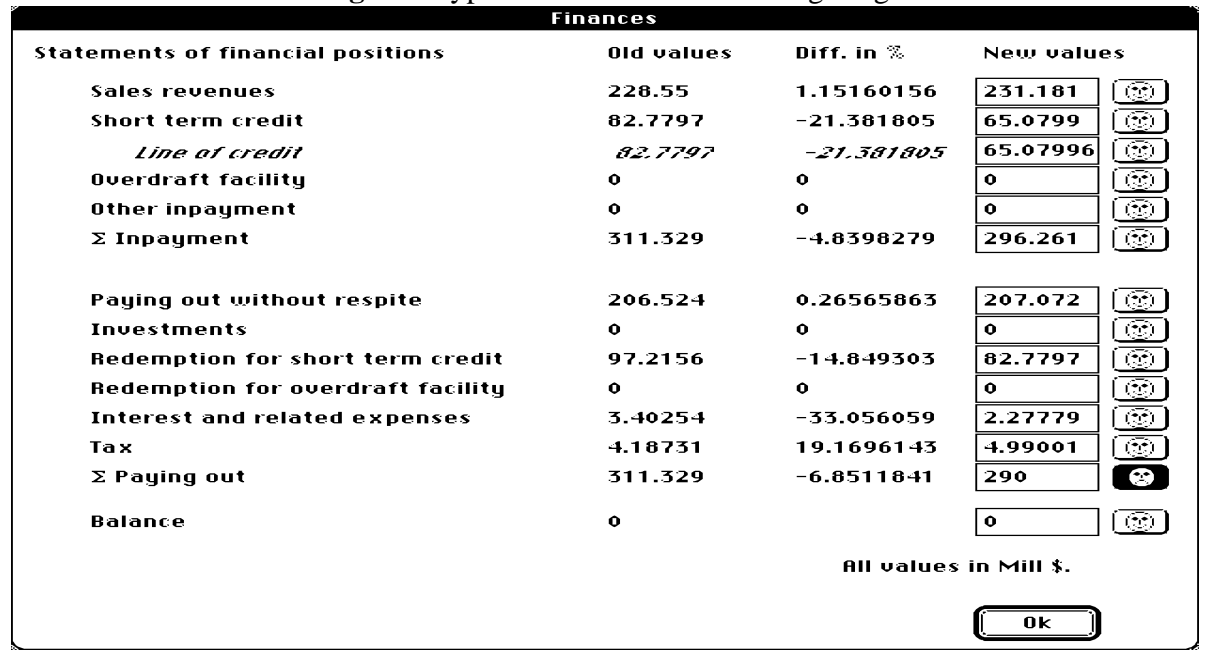

Fig. 6. Feedback to the hypothesis for internal budgeting 


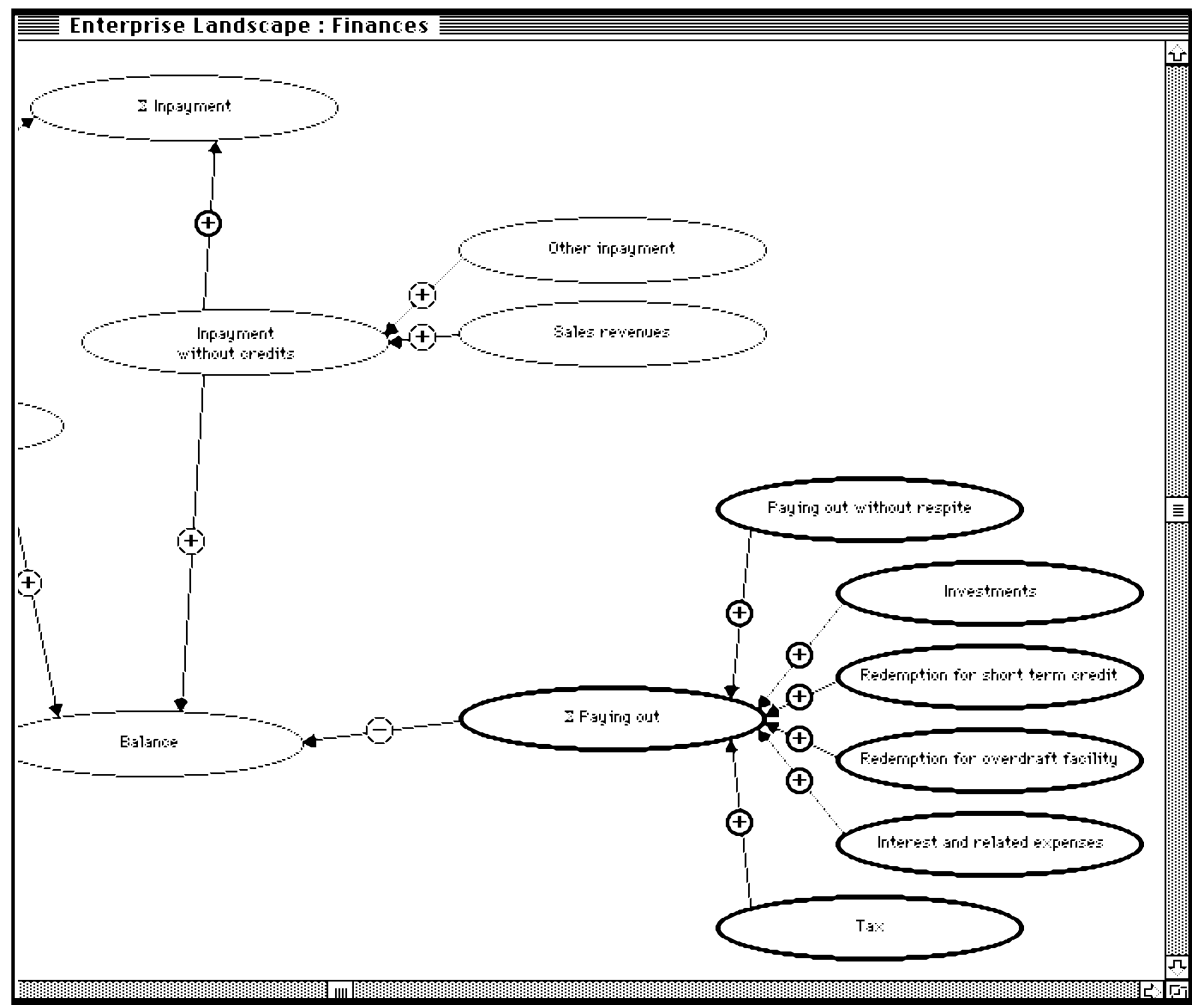

Fig. 7. Part of the Landscape of WULPUS

\section{Conclusions}

We redesigned a "classical" forward chaining business game. The new game, WULPUS, is "backward chaining" and "goal oriented", thus supporting our hypotheses testing approach. According to our ISP-DL knowledge acquisition theory, hypotheses testing takes place at impasse time when there are knowledge deficiencies on the learner's side.

There is strong empirical evidence that system support in those impasse situations is more efficient than in other problem solving situations. We put forward the empirically testable hypothesis that learners working with the IPSE WULPUS gain more procedural knowledge in less time.

\section{References}

ANDERSON, J. R., The Architecture of Cognition, Cambridge: Harvard Univ. Press, 1983 ANDERSON, J. R., A Theory of the Origins of Human Knowledge, Artificial Intelligence, 1989, 40, 313-351

CADOTTE, E. R., The Market Place, A Strategic Marketing Simulation, Richard D. Irwin, Inc., 1990 
ESER, T. W., Planspiel kommunale Wirtschaftsförderung, in H. SPEHL (Hrgs.), Trierer Schriftenreihe zum Schwerpunkt Tourismus, Regional- und Siedlungsentwicklung Nr. 3, Universität Trier, 1992

GOLlWITZER, P. M., Action Phases and Mind-Sets, in E.T. HIGGINS \& R.M. SORRENTINO (eds), Handbook of Motivation and Cognition: Foundations of Social Behavior, 1990, Vol. 2, 53-92

HECKHAUSEN, H., Motivation und Handeln, Berlin: Springer, 1989

LAIRD, J. E. , ROSENBLOOM, P. S. \& NEWELL, A., Universal Subgoaling and Chunking. The Automatic Generation and Learning of Goal Hierarchies, Boston: Kluwer, 1986

MÖBUS, C., Towards an Epistemology of Intelligent Problem Solving Environments: The Hypothesis Testing Approach, in: J. GREER (ed), Proceedings of AI-ED 95, World Conference on Artificial Intelligence and Education, 1995, 138-145

MÖBUS, C., SCHRÖDER, O. \& THOLE, H.-J., Diagnosing and Evaluating the Acquisition Process of Programming Schemata, in: J. E. GREER \& G. McCALLA (eds), Student Modelling: The Key to Individualized Knowledge-Based Instruction (Proc. of the NATO Advanced Research Workshop on Student Modelling, in St. Adele, Quebec, Canada, Berlin: Springer (NATO ASI Series F: Computer and Systems Science, Vol. 125), 1994, 211-264

MÖBUS, C., THOLE, H.-J. \& SCHRÖDER, O., Interactive Support of Planning in a Functional, Visual Programming Language, in P. BRNA, S. OHLSSON, H. PAIN (eds), Proceedings AI-ED 93, World Conference on Artificial Intelligence and Education, Edinburgh, 1993, 362 - 369

NEWELL, A., Unified Theories of Cognition, Cambridge: Harvard Press, 1990

SHUTE, V. J. \& GLASER, R., A Large-Scale Evaluation of an Intelligent Discovery World: Smithtown, Interactive Learning Environments, 1, 1990, 51-77

Van LEHN, K., Toward a Theory of Impasse-Driven Learning, In: H. MANDL \& A. LESGOLD (eds), Learning Issues for Intelligent Tutoring Systems, New York: Springer, 1988, 19-41

Van LEHN, K., Rule Acquisition Events in the Discovery of Problem Solving Strategies, Cognitive Science, 1991, 15, 1- 47 